\title{
A RARE CASE REPORT OF SYPHILIS MIMICKING AN OROPHARYNGEAL NEOPLASM
}

\author{
Sofia Kalantary ${ }^{1 \mathrm{a}}$, Christophe Politis ${ }^{2 \mathrm{~b}^{\star}}{ }^{(\mathbb{C}}$, Wouter De $\operatorname{Vos}^{1,3 \mathrm{c}}$, Sten Stevens ${ }^{1 \mathrm{~d}}$, Maarten Van Genechten ${ }^{1,3 e}$, \\ Herman Jr Vercruysse ${ }^{1,3 f}$, Geert Van Hemelen ${ }^{19}$
}

'ZMACK / Associatie MKA, AZ Monica Antwerp, Belgium

2Department of Maxillofacial Surgery, Hôpital Erasme, Université Libre de Bruxelles - ULB, Brussels, Belgium

${ }^{3}$ Department of Cranio-Maxillofacial Surgery, Antwerp University Hospital, Z.M.A.C.K association of Antwerp

aMD, DDS, Maxillofacial Surgery Resident; e-mail: kalantarysofia89@gmail.com;

bMD, DDS, Maxillofacial Surgery Resident; e-mail: christophe.politis@gmail.com; ORCIDiD: https://orcid.org/0000-0002-1076-1327

cMD, DDS, Maxillofacial Surgeon; e-mail: de.vos.w@gmail.com;

dMD, DDS, Maxillofacial Surgeon; e-mail: sten.stevens@gmail.com;

eMD, DDS, Maxillofacial Surgeon; e-mail: maartenvangenechten@telenet.be;

'MD, DDS, Maxillofacial Surgeon; e-mail: juni90@hotmail.com;

9MD, DDS, Maxillofacial Surgeon; e-mail: drvanhemelen@azmonica.be;

ABSTRACT

d) https://doi.org/10.25241/stomaeduj.2021.8(1).art. 8

Aim Syphilis is a widely spread, sexually transmitted disease that is often considered archaic, but it has been on the rise in recent years. The oropharyngeal region is an uncommon location for treponema pallidum to present itself. It is even more uncommon when, on a radiological evaluation, it is diagnosed as a neoplasm or squamous cell carcinoma. This case report discusses a rare case of syphilis that mimics an oropharyngeal carcinoma.

Summary The patient presented himself initially with cervical lymphadenopathies and an oropharyngeal lesion. On the MRI scan, the lesion was suspicious for an oropharyngeal squamous cell carcinoma. Multiple negative biopsies $(2 \mathrm{X})$ urged the search for an alternative diagnosis. After serologic testing, it became clear the patient was suffering from syphilis. Syphilis is known as the "great pretender" and can present in a nonspecific manner.

Key learning points

i) Syphilis is known as the "great pretender".

ii) Treponema pallidum infections need to be taken into account as a differential diagnosis in patients with an oropharyngeal lesion.

iii) Syphilis is on the rise.

iv) Syphilis has the ability to mimic a malignancy upon clinical presentation.

v) Syphilis has the ability to mimic a malignancy on CT and MRI-imaging.

\section{KEYWORDS}

Syphilis; Cervical Lymph Node; Oropharyngeal Ulceration; Carcinoma; Mimicking.

\section{INTRODUCTION}

An increasing incidence of syphilis is inherently related to an increasing number of atypical presentations of the disease. Syphilis is on the rise and, with the increase in cases, there has been an increase in different and unusual presentations of the disease.
Since 2010, reports of syphilis incidence rates in the European Union (EU) have been ever increasing. This trend seems to be accelerating, predominantly amongst male homosexuals [1]. Syphilis is a sexually transmitted infection caused by Treponema pallidum, a well-known pathogen that can cause pathology in the maxillofacial area. Although there is little

(c) (1) (3) OPEN ACCESS This is an Open Access article under the CC BY-NC 4.0 license. Peer-Reviewed Article

Citation: Kalantary S, Politis C, De Vos W, Stevens S, Van Genechten M, Vercruysse Jr H, Van Hemelen G. A rare case report of syphilis mimicking an oropharyngeal neoplasm. Stoma Edu J. 2020;7(4):78-82

Received: February 06, 2021; Revised: February 10, 2021; Accepted: February 13, 2021; Published: February 15, 2021

*Corresponding author: Dr. Christophe Politis, Department of Maxillofacial Surgery, Hôpital Erasme, Université Libre de Bruxelles - ULB,

Route de Lennik 808, B-1070 Bruxelles, Belgium

Tel: +32 (0)2 555 4474; Fax: +32 (0)2 555 4599; e-mail: Christophe.politis@gmail.com;

Copyright: $\odot 2020$ the Editorial Council for the Stomatology Edu Journal. 
literature describing oropharyngeal treponema pallidum infections as mimicking an oropharyngeal squamous cell carcinoma (OPSCC), it has been described in rare cases [2]. This case report presents such a case.

Ulcers of the oral cavity and the oropharynx are frequently encountered in maxillofacial practices around the world. Consequently, the differential diagnosis of oral and oropharyngeal ulcers is an important one. A wide range of causes for oral or oropharyngeal ulcers are reported, such as aphthous, traumatic, malignant, tuberculosis, HIV and AIDS (Table 1).

Ulcers can also present associated with skin lesions [3]. Most of these ulcers are promptly diagnosed and treated because the oral or oropharyngeal subsite and the anamnesis are often positive indicators for diagnosis. An important differential diagnostic criterium for traumatic ulcerations is if healing occurs after removal of the probable cause. It is important however to distinguish innocent solitary ulcerations from malignant lesions, such as squamous cell carcinomas. Lesions that persist longer than 3 weeks should be considered as malignant until proven otherwise.

A tuberculous ulcer is rare, almost always secondary to lung tuberculosis and preferably located on the tongue (or lips). It is often not painful and regional lymphadenopathy is usually present. A rare cause of chronic solitary ulcers is syphilitic ulceration. Ulcer usually develops on the lips and, rarely, on the tongue, the pharynx, or the tonsils [4]. In even more rare cases, the ulcer will present itself mimicking a neoplasm in the oropharynx on a clinical and a radiological basis. Hence, it has been named "the great pretender" [5].

\section{CASE REPORT}

A 35-year-old male with no significant medical history was referred to the Cranio-Maxillo-Facial department of the University Hospital of Antwerp, Belgium with swallowing difficulty and minor pain in the throat for the last two months. He suffered from significant fatigue and unexplained weight loss of $10 \mathrm{~kg}$ in the previous months. He noticed a swelling of the left oropharynx and multiple bilateral lumps in his neck. There was no history of smoking, oncological disorders, or a familial predisposition to cancer. The patient claimed to have no risk factors for sexually transmitted diseases and no sexual contact for a longer period of time.

Clinical examination revealed an ulcerative mass of $30 \mathrm{~mm}$ by $50 \mathrm{~mm}$ in size in the left oropharynx (Fig. 1). The ulceration was associated with moderate pain complaints.

The patient had multiple swollen cervical lymph nodes, which were painless. No facial deformities or any neurological abnormalities were noted. The thyroid gland presented normal upon swallowing and was not enlarged. Further intra-oral examination of the tonsils, mucosa, hard and soft palate, floor of the mouth, dentition, and tongue showed no abnormalities.

\section{RADIOGRAPHIC EXAMINATION}

A multi-slice computerized tomography scan (CT) with iodine contrast revealed an irregular lining on the left of the posterior wall of the oropharynx (Fig. 2). Furthermore, the scan showed a slight retropharyngeal gray area without any collection or fluid build-up.

There were multiple lymphadenopathies in the neck, at levels II to III on the left side and on level II on the right side. In addition, a magnetic resonance imaging (MRI) scan was performed to further investigate this soft tissue lesion. The MRI scan showed an oropharyngeal lesion compatible with an oropharyngeal carcinoma (Fig. 3). There was no extranodal extension in the neck. As an oropharyngeal squamous cell carcinoma was suspected, a diagnostic biopsy was performed.

\section{PATHOLOGY}

Two negative biopsies were taken by an ENT surgeon before referral. Because the clinical presentation was very suggestive for malignancy, a fiberoptic inspection under general anesthesia with biopsies was performed at our center.

The biopsy showed mucosal ulceration and a dense chronicinflammation with mixed lymphoplasmacytic infiltrate. No monoclonal cell population was detectable, and there was no evidence of dysplasia or epithelial malignancy.

\section{DIAGNOSIS}

Although the clinical and radiologic presentation was very suspect for an oropharyngeal carcinoma, multiple negative biopsies ruled out a malignancy. Alternative diagnoses were investigated and a differential diagnosis was made. After performing extensive laboratory tests, the diagnosis of an active syphilis was confirmed.

Blood tests showed a positive Treponema pallidum RPR (Rapid Plasma Regain) in combination with highly elevated titers in the Treponema Pallidum particle Hemagglutination Assay (TPHA). The TPHA test is a very sensitive treponemal test (sensitivity $>95 \%$ and specificity $>99 \%$, qualitative mean accuracy, $91.4 \%$; range, 56.1 to $98.2 \%$; quantitative mean accuracy, 75.4; range, 55.5 to $95.5 \%$ ) [6].

In this case, the TPHA was $>20280$ which indicated the presence of treponema pallidum. In addition to the TPPA result, a RPR (Rapid Plasma Regain, nontreponemal test) was performed, with a positive result (titer 2 ).

The results of this nontreponemal test is semiquantitative, reflecting the activity of the 


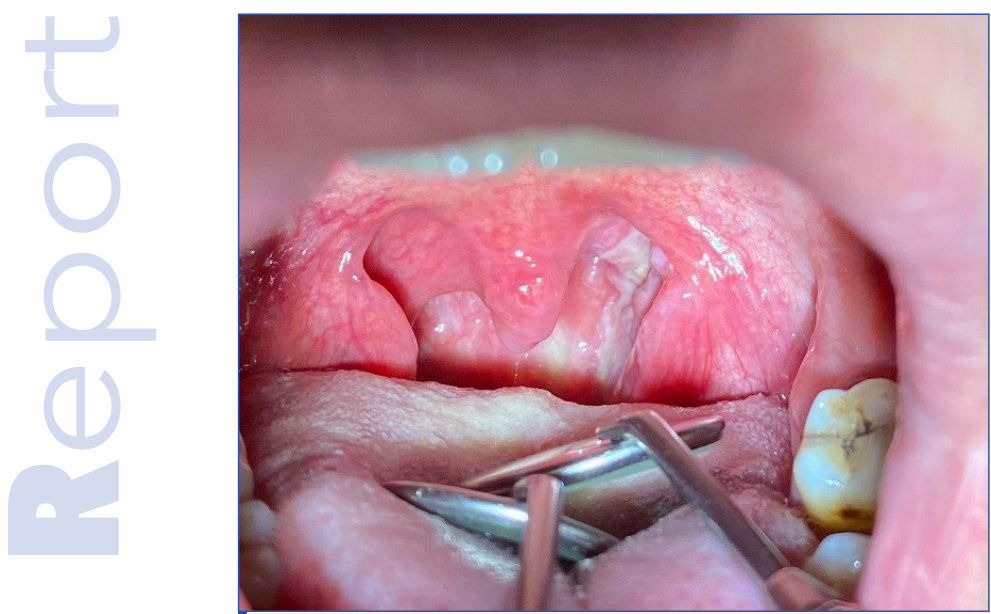

Figure 1. Ulcerative lesion seen in the left oropharynx.

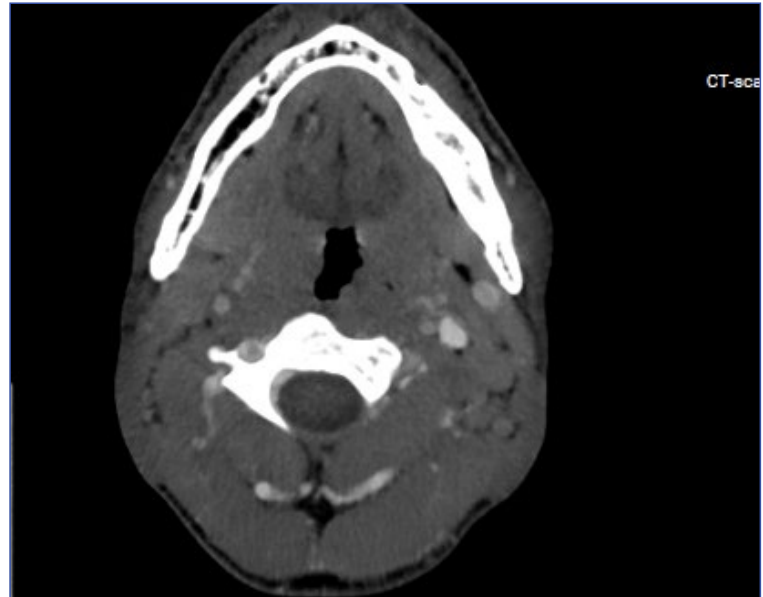

Figure 2. Axial section of a CT scan of the head and neck showing an ir regular posterior wall of the oropharynx.

ITable 1. Differential diagnosis for oral/oropharyngeal ulcers.

\begin{tabular}{|l|l|}
\hline Traumatic & Syphilis \\
\hline Malignant & Tuberculosis \\
\hline $\begin{array}{l}\text { latrogenic (radiotherapy, chemotherapy, antiresorptive } \\
\text { medication, etc.) }\end{array}$ & $\begin{array}{l}\text { Recurrent, painful ulcerations (Behçet's disease, chemotherapy, } \\
\text { radiotherapy, herpetic, aphtous, etc.) }\end{array}$ \\
\hline
\end{tabular}

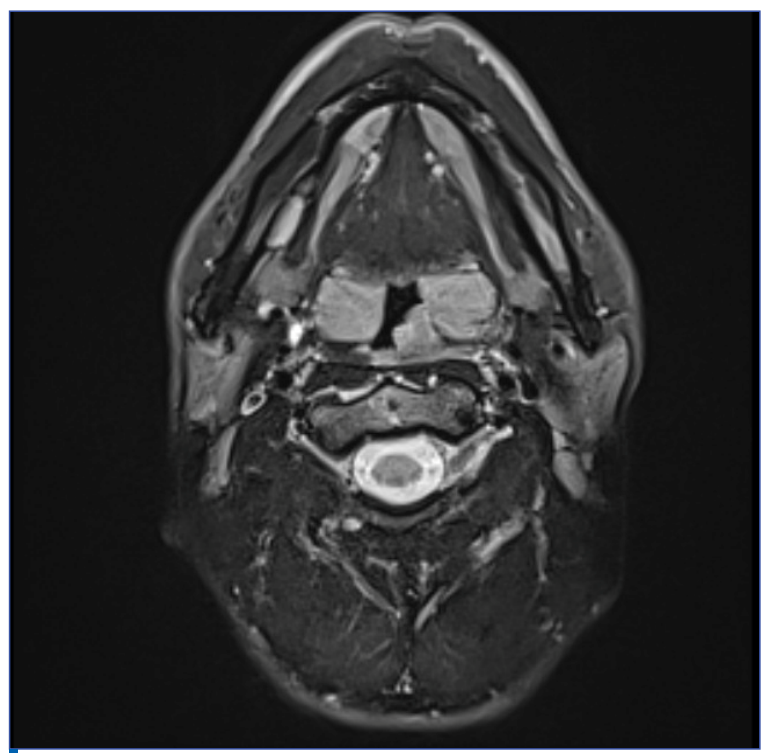

Figure 3. Axial section of an MRI scan of the head and neck showing an oropharyngeal lesion compatible with an oropharyngeal carcinoma.

infection [7]. Given the clinical presentation and serologic testing, the diagnosis of a primary/early secondary active syphilis was made. HIV testing was negative, as was the screening for Chlamydia, Hepatitis B and C, and gonorrhea.

\section{TREATMENT}

The patient was referred to the infectious disease specialist and his general practitioner (GP) for treatment with benzathine penicillin intramuscular (2.4 million IE, one day treatment) [8].

After 3 weeks the patient was seen on consultation, and the lesion and the discomfort had disappeared.

\section{DISCUSSION}

Due to the rising number of cases of syphilis, syphilitic lymphadenitis is an important differential diagnosis for patients presenting with cervical lymphadenopathy and oropharyngeal lesions [9]. Clinicians should be aware that syphilis can also present as a squamous cell carcinoma-like lesion in most oral subsites [10]. In this case, the patient presented with weight loss, fatigue, cervical lymphadenopathies, an oropharyngeal lesion, and an MRI scan that suggested a possible oropharyngeal squamous cell carcinoma. Because multiple biopsies were negative for malignancy, an alternative diagnosis was eventually made.

It has to be mentioned, that there are different techniques to obtain an oropharyngeal biopsy, and a false-negative result may be possible if the technique employed is not optimal. In case of doubt, a new biopsy should be taken and retaken by the same surgeon, taking into account that an incision biopsy at the exact location of the lesion is the most sensitive. We advise against fineneedle aspiration cytology of ulcerative lesions because of its lower sensitivity and specificity, which are respectively $71.4 \%$ and $97.8 \%$ [11]. Syphilis can evolve into four stages, each with certain characteristics (Table 2). Given the absence of mucous patches or maculopapular lesions, and the local presentation, a working diagnosis of primary syphilis was made [12].

Tamura et al. (2008) described a case similar to the one presented in this report [13]. His patient presented with an oropharyngeal tumor and a cervical lymphadenopathy with the primary lesion being 
I Table 2. Most important characteristics of the four syphilitic stages.

\begin{tabular}{|l|l|l|}
\hline Stages & Timing & Characteristics \\
\hline Primary & 3-4 weeks incubation & Painless chancre at the site of infection \\
\hline$\underline{\text { Secondary }}$ & $\begin{array}{l}4-10 \text { weeks after infection } \\
\text { Latent }\end{array}$ & $\begin{array}{l}\text { Rash, systemic symptoms (fever, weight loss, } \\
\text { fatigue), headache, mucous membrane lesions } \\
\text { throughout body }\end{array}$ \\
\hline Tertiary & $\begin{array}{l}\text { Early latent }(<1 \text { year after infection) } \\
\text { Late latent }>1 \text { year after infection) }\end{array}$ & Asymptomatic, diagnosis through serologic testing \\
\hline & $1-10$ years after infection & $\begin{array}{l}\text { Gummatous lesions, Cardiovascular issues, CNS } \\
\text { disorders }\end{array}$ \\
\hline
\end{tabular}

strongly suggestive for oropharyngeal cancer. Eventually this case was diagnosed with oropharyngeal syphilis. As a FDG-PET scan was performed as part of a staging procedure, their work-up slightly differed from ours. Since FDG is not specific for malignancy, it will also accumulate in many benign processes such as inflammatory, post-traumatic or benign tumours. Preferably incisional qualitative biopsy should be taken before imaging FDG-PET scan is considered.

\section{CONCLUSION}

Treponema pallidum infections need to be taken into account as a differential diagnosis in patients with an oropharyngeal lesion when histopathological results exclude malignancy. Syphilis is known as the 'great pretender', in their ability to mimic a malignancy upon clinical presentation and on CT and MRI-imaging.

\section{CONFLICT OF INTEREST}

The authors declare that they have no competing interest.

\section{ACKNOWLEDGMENTS}

There are no conflicts of interest and no financial interests to be disclosed.

\section{AUTHOR CONTRIBUTIONS}

$\mathrm{SK}, \mathrm{CP}, \mathrm{HV}$ wrote the manuscript in consultation with WD and GV. All authors provided critical feedback and helped shape the research and the manuscript. SS and MV aided in interpreting the results.

\section{REFERENCES}

1. European Centre for Disease Prevention and Control. Syphilis and congenital syphilis in Europe. A review of epidemiological trends (2007-2018) and options for response. ECDC Technical Report. Stockholm: ECDC; 2019. [Internet]. [cited 2021 Jan 11]. Available from: https://www.ecdc.europa.eu/sites/default/files/ documents/syphilis-and-congenital-syphilis-in-Europe.pdf 2. Jategaonkar A, Klimczak J, Agarwal J, et al. Syphilis of the oropharynx: Case series of "The Great Masquerader". Am J Otolaryngol. 2019;40(2):143-146. doi: 10.1016/j. amjoto.2019.01.005. PMID: 30661890.

Full text links PubMed Google Scholar Scopus WoS

3. Thimmappa TD, Ramesh S, Shetty HS, Gangadhara KS. Aetiopathology of ulcers of oral cavity and oropharynx: a cross sectional study. Int J Res Med Sci. 2013;1(4):496-500. doi: 10.5455/2320-6012.ijrms20131135. CrossRef 4. Mortazavi H, Safi Y, Baharvand M, Rahmani S. Diagnostic features of common oral ulcerative lesions: an updated decision tree. Int J Dent. 2016;2016:7278925. doi: 10.1155/2016/7278925. PMID: 27781066; PMCID: PMC5066016.

Full text links Free PMC Article CrossRef PubMed Google Scholar Scopus WoS

5. Pisani Ceretti A, Virdis M, Maroni N, et al. The great pretender: rectal syphilis mimic a cancer. Case Rep Surg. 2015;2015:434198. doi: 10.1155/2015/434198. PMID: 26451271; PMCID

PMC4586962.

Full text links $\underline{\text { Free PMC Article CrossRef PubMed Google Scholar }}$ WoS

6. Müller I, Brade V, Hagedorn $\mathrm{HJ}$, et al. Is serological testing a reliable tool in laboratory diagnosis of syphilis? Meta-analysis of eight external quality control surveys performed by the german infection serology proficiency testing program. J Clin Microbiol. 2006:44(4):1335-1341. doi: 10.1128/JCM.44.4.1335-1341.2006. PMID: 16597859; PMCID: PMC1448642.

Full text links Free PMC Article PubMed Google Scholar

7. Henao-Martínez AF, Johnson SC. Diagnostic tests for syphilis: New tests and new algorithms. Neurol Clin Pract. 2014;4(2):114122. doi: 10.1212/01.CPJ.0000435752.17621.48. PMID: 27606153; PMCID: PMC4999316.

Free PMC Article PubMed Google Scholar
8. The Federal Public Service (FPS) Health, Food Chain Safety and Environment. [The Belgian Guide to anti-infective treatment in outpatient practice 2019 of BAPCOC has been updated].

[Internet]. [cited 2021 Jan 11]. Available from: https://www. health.belqium.be/sites/default/files/uploads/fields/fpshealth theme file/belgische gids bapcoc nl 2021 a4 2.pdf 9. Ikenberg K, Springer E, Bräuninger W, et al. Oropharyngeal lesions and cervical lymphadenopathy: syphilis is a differential diagnosis that is still relevant. J Clin Pathol. 2010;63(8):731-736. doi: 10.1136/jcp.2010.077586. PMID: 20702475.

Full text links PubMed Google Scholar Scopus WoS

10.Solis RN, Kuhn BT, Farwell DG. An unusual case of tertiary syphilis behaving like tongue squamous cell carcinoma. $J$ Investig Med High Impact Case Rep. 2018;6:2324709618820355. doi:10.1177/2324709618820355. PMID: 30622992; PMCID:

PMC6302270.

Full text links Free PMC Article PubMed Google Scholar Scopus WoS 11. Gupta N, Banik T, Rajwanshi A, et al. Fine needle aspiration cytology of oral and oropharyngeal lesions with an emphasis on the diagnostic utility and pitfalls. J Cancer Res Ther. 2012;8(4):626629. doi: 10.4103/0973-1482.106581. PMID: 23361285.

CrossRef PubMed Google Scholar Scopus WoS

12. French P. Syphilis. BMJ. 2007;334(7585):143-147. doi: 10.1136/ bmj.39085.518148.BE. Erratum in: BMJ. 2007;335(7617):0. PMID:

17235095; PMCID: PMC1779891.

Free PMC Article CrossRef PubMed

13. Tamura S, Takimoto Y, Hoshida Y, et al. A case of primary oropharyngeal and gastric syphilis mimicking oropharyngeal cancer. Endoscopy. 2008;40 Suppl 2:E235-E236. doi: 10.1055/s2008-1077679. PMID: 18991216.

Full text links CrossRef PubMed Google Scholar Scopus WoS 
MD, DDS, Maxillofacial Surgery Resident ZMACK / Associatie MKA AZ Monica Antwerp, Belgium

Dr. Sofia Kalantary is a resident in Oral and Maxillofacial Surgery at the University of Antwerp, Antwerp, Belgium. She has a clinical focus in orthognathic and dento-alveolar surgery. During her training she spent two years at the St. Elisabeth Hospital, Tilburg in the Netherlands where she was trained by JPO Scheerlinck. For the last two years of her residency she specialized in the field of orthognathic surgery and 3D surgical planning at the ZMACK / MKA association of Antwerp, Belgium.

\section{Questions}

\section{Syphilis is a sexually transmitted infection caused by}

口a. Treponema pallidum;

ab. Actinomyces;

ac. Streptococcus salivarius;

$\square$ d. Neisseria gonorrhoeae.

\section{Primary syphilis has an incubation time of}

Da. 6 months;

ab. 3-4 weeks;

口c. 4-10 weeks;

ad. 1 day.

\section{Syphilis has the ability to mimick}

口a. Dental caries;

b. Periodontal disease;

ac. Neuropathic pain;

$\square$ d. A malignancy on CT- and MRI-imaging.

\section{An oral/oropharyngeal ulcer cannot be one of the following}

a. Syphilis;

口b. Traumatic ulcer;

Dc. Malignant;

口d. Hemangioma. 